\section{Imunohistoquímica como método de estudo das fibras elásticas em prega vocal humana}

\author{
Hugo Valter Lisboa Ramos ${ }^{1}$, Manuel de Jesus \\ Simões ${ }^{2}$, Paulo Augusto de Lima Pontes ${ }^{3}$, Luciano \\ Rodrigues Neves ${ }^{4}$ Luiz Henrique Fonceca Barbosa ${ }^{5}$, \\ Noemi Grigoletto De Biase ${ }^{6}$, Celina T.S. Osbima ${ }^{7}$
}

\section{Immunohistochemistry as a method to study elastic fibers of human vocal fold}

Resumo / Summary

$\mathbf{O}_{\text {o }}$ aplicabilidade do método imunohistoquímico na quantificação das diferentes formas das fibras elásticas em prega vocal humana. Forma de estudo: coorte transversal. Material e método: Foram seguidos os seguintes critérios de inclusão: idade entre 25 e 40 anos, gênero masculino, cor branca, morte causada por ferimento de arma de fogo, menos de doze horas de morte, ausência de intubação traqueal e de trauma na região cervical e que, por análise microscópica, não apresentassem qualquer alteração da mucosa das pregas vocais. Por estes critérios dez pregas vocais foram obtidas e selecionou-se, aleatoriamente, uma prega vocal que pertencia a um indivíduo de 28 anos. A prega vocal foi transversalmente seccionada em nove regiões e três cortes de cada fragmento foram utilizados para a realização das colorações Verhoeff e resorcina-fuchsina de Weighert e para a realização do estudo imunohistoquímico. Realizou-se quantificação colorimétrica das fibras elásticas. Resultado: As camadas intermediária e profunda da prega vocal apresentam valores muito superiores aos da camada superficial, nas colorações histológicas. A quantidade de tropoelastina identificada pelos anticorpos não apresentou grandes diferenças entre os valores da camada superficial e os da camada intermediária e profunda. Conclusão: A imunohistoquímica é uma técnica que identifica, em prega vocal humana, todas as formas de fibras elásticas e que também possibilita a realização de medidas objetivas.
Palavras-chave: laringe, prega vocal, elastina, imunohistoquímica.

Key words: larynx, vocal fold, elastin, immunohistochemistry.

\begin{abstract}
Aim: Verify the use of immunohistochemistry as a method to measure all forms of elastic fibers at human vocal folds. Study design: transversal cohort. Material and method: We collected vocal folds following these criterion: age between 25 and 40, Caucasian men, dead by gun shot, within 12 hours of death, without instrumentation of the larynx or suspicion of neck injury and without mucosal lesions noted by microscopy. Ten vocal folds were collected and one, of a man aged 28 years, was selected to study. The vocal fold was transversely cut in 9 regions and in each segment three slides were made. These slides were stained by Verhoeff and Weighert's resorcin-fuchsin and used for immunohistochemistry. The elastic compound was measured by colorimetric software analysis. Results: In Verhoeff and Weighert's resorcin-fuchsin, the intermediate and deep layer showed values higher than those of the superficial layer. The amount of tropoelastin identified by the antibody at the superficial layer was close to those of intermediate and deep layer. Conclusions: Immunohistochemistry is a method that can identify and measure all forms of elastic fibers at human vocal fold.
\end{abstract}

Otorrinolaringologista (Pós-Graduando)

${ }^{2}$ Doutor (Professor da UNIFESP-EPM).

${ }^{3}$ Doutor em Medicina (tese de Doutoramento) pela Escola Paulista de Medicina, 1970. Doutor em Medicina (tese de Doutorado) ao nível de curso de pós-graduação pela Escola Paulista de Medicina, 1981. Livre-Docente pela Disciplina de Otorrinolaringologia do Departamento de Oftalmo/Otorrinolaringologia da Escola Paulista de Medicina, 1989. Professor Titular pelo Departamento de Otorrinolaringologia e Distúrbios da Comunicação Humana da Escola Paulista de Medicina, 1991.

${ }^{4}$ Pós-graduando da UNIFESP-EPM.

${ }^{5}$ Otorrinolaringologista (Pós-graduando). ${ }^{6}$ Doutora.

7 Doutora (Bióloga)

Artigo recebido em 08 de março de 2005 . Artigo aceito em 20 de junho de 2005.

Revista Brasileira de Otorrinolaringologia 71 (4) Parte 1 Julho/Agosto 2005

http://www.rborl.org.br / e-mail: revista@aborlccf.org.br

486 


\section{INTRODUÇÃO}

A fisiologia da produção do som pelas pregas vocais mantém íntima relação com as características da lâmina própria (LP) da prega vocal. Hirano ${ }^{1}$ estabeleceu a relação entre a estrutura trilaminar da LP e o processo vibratório e destacou a importância da camada superficial, constituída por um tecido frouxo com poucas fibras colágenas e elásticas, e da camada intermediária (CI), composta principalmente por fibras elásticas.

A identificação das fibras elásticas até o ano de 1997 era realizada por meio de análise subjetiva baseada na observação do pesquisador. Neste ano, Hammond et al. ${ }^{2}$ apresentaram um estudo utilizando um sistema de quantificação colorimétrica do tecido elástico corado pela técnica Verhoeff e compararam os resultados com a microscopia eletrônica (ME). Por meio deste sistema, que permite análise estatística dos resultados, os autores demonstraram que as fibras elásticas concentram-se preferencialmente na CI da lâmina própria.

A ME também tem sido utilizada por autores como Ishii et al. ${ }^{3}$ e Sato \& Hirano ${ }^{4}$ e, atualmente, é considerada como o método que melhor identifica as diferentes proteínas fibrosas da prega vocal. Apresenta grande especificidade na identificação das fibras elásticas elaunínicas e oxitalânicas já que as distingue baseando-se na sua forma. No entanto, esse método não possibilita a quantificação das estruturas.

Até onde pudemos pesquisar, não há nenhum estudo que utilize a imunohistoquímica para a identificação das fibras elásticas na prega vocal humana. Do mesmo modo que o método ultra-estrutural, o anticorpo permite que as fibras elásticas sejam identificadas em todas as suas formas. Porém permite a quantificação das fibras de modo muito específico, sem a interferência de outras estruturas que porventura também estejam coradas.

O objetivo deste trabalho é o de verificar a aplicabilidade do método imunohistoquímico na quantificação das diferentes formas das fibras elásticas em prega vocal humana.

\section{MATERIAL E MÉTODO}

Estudo experimental desenvolvido nos Departamentos de Otorrinolaringologia e Cirurgia de Cabeça e Pescoço, Patologia e Morfologia da UNIFESP - EPM. O estudo foi aprovado pelo Comitê de Ética em Pesquisa da Universidade Federal de São Paulo/Hospital São Paulo.

Foram seguidos os seguintes critérios de inclusão: idade entre 25 e 40 anos, gênero masculino, cor branca, morte causada por ferimento de arma de fogo, menos de doze horas de morte, ausência de intubação traqueal e de trauma na região cervical e que, por análise microscópica, não apresentassem qualquer alteração da mucosa das pregas vocais.
Por estes critérios dez pregas vocais foram obtidas e selecionou-se, aleatoriamente, uma prega vocal que pertencia a um indivíduo de 28 anos.

A prega vocal foi colocada em solução de formaldeído a 10\% tamponado para fixação dos tecidos e, posteriormente, foi processada pela técnica usual de parafinização. Após estar impregnada pela parafina, a prega vocal foi transversalmente seccionada em nove regiões. Os fragmentos estendiam-se da extremidade anterior da prega vocal - nomeada fragmento 1 - até a extremidade posterior, junto ao processo vocal da cartilagem aritenóidea - fragmento 9.

De cada fragmento da prega vocal foram retirados 3 cortes com 4 micrômetros de espessura para confecção das lâminas para estudo histológico e imunohistoquímico. Dois cortes de cada fragmento foram utilizados para a realização das colorações Verhoeff e resorcina-fuchsina de Weighert e o terceiro corte foi utilizado para a realização do estudo imunohistoquímico. Foi utilizado anticorpo policlonal contra tropoelastina humana, que é a subunidade solúvel responsável pela formação da porção amorfa da elastina (Midwood ${ }^{5}$ ), obtido a partir de soro de coelhos imunizados e fabricado pelo laboratório EPC (PR398, Polyclonal Antiserum to Human Tropoelastin). Para a realização do estudo imunohistoquímico utilizou-se o anticorpo na diluição de 1:800 obtida após estudo piloto.

As lâminas foram analisadas por meio de estudo histomorfométrico comparando-se a intensidade das cores nas camadas superficial, intermediária e profunda da lâmina própria. Para localização das camadas da lâmina própria e escolha do campo histológico a ser analisado utilizamos algumas referências histológicas. A camada superficial foi definida como o tecido que de forma homogênea se localizava na adjacência do epitélio e que possuía limites profundos bem nítidos. A camada intermediária foi definida como a que de forma homogênea se situasse na adjacência da camada superficial e a camada profunda foi definida como a região da lâmina própria que mantinha estreita relação com o músculo tiroaritenóideo, já que os limites entre as camadas intermediária e profunda não se mostraram nítidos pelas técnicas histológicas e imunohistoquímicas empregadas. Os limites foram inicialmente identificados em um aumento de 40 vezes.

As imagens foram captadas através de uma câmera digital (Sony Hyper HAD) acoplada a um microscópio de luz (Laboval 4) e conectada a um computador com placa Captvator, utilizando-se aumento de 400 vezes. A imagem foi processada pelo software DIRACOM3 desenvolvido no Laboratório de Informática Dedicado à Odontologia (LIDO), do Departamento de Estomatologia da Faculdade de Odontologia da Universidade de São Paulo e, atualmente, atualizado e comercializado com o nome de Imagelab $2000^{\circledR}$. $\left(\right.$ Novelli $\left.{ }^{6}\right)$.

Esse software permite identificar, selecionar e subtrair estruturas de uma imagem por meio dos espectros R ( red), G (green) e B (blue), utilizando 126 tons de vermelho, 126 
de azul e 126 de verde. Quanto maior for o número de tons de vermelho, azul ou verde e suas combinações no tecido estudado, maiores serão as probabilidades de separar estruturas dentro dos seus limites. O computador faz a varredura de toda a imagem, comparando o valor da cor de cada pixel com uma tabela de padrões previamente selecionados. Se o valor corresponder a algum presente na tabela, este é subtraído da imagem, de tal forma que permanecem somente as estruturas formadas pelos pixels diferentes daqueles pertencentes ao padrão selecionado. Ao final, o computador informa a porcentagem das áreas removidas em relação à área da imagem original (Figura 1).

Neste estudo utilizamos a cor verde para selecionarmos os pixels que correspondiam às fibras elásticas nas diferentes colorações. Nas colorações Verhoeff e resorcin-fuchsin de Weighert foi medida a cor preta e na imunohistoquímica medimos a cor marrom.

Os resultados foram analisados descritivamente.

\section{RESULTADOS}

As Tabelas 1, 2 e 3 mostram a quantidade de tecido elástico presente na LP da prega vocal que pôde ser medida nas diferentes colorações. Os valores encontrados foram distribuídos de acordo com a região da prega vocal e com a camada da LP estudada. Esses valores correspondem à porcentagem da área das cores selecionadas pelo software Imagelab $2000^{\circledR}$ em relação à área da imagem original.

As Figuras 2, 3, e 4 mostram a distribuição das fibras elásticas nas camadas superficial, intermediária e profunda, nas colorações Verhoeff, resorcin-fuchsin de Weighert e na imunohistoquímica.

Analisando os valores obtidos na coloração Verhoeff e resorcin-fuchsin de Weighert, pôde-se observar que as

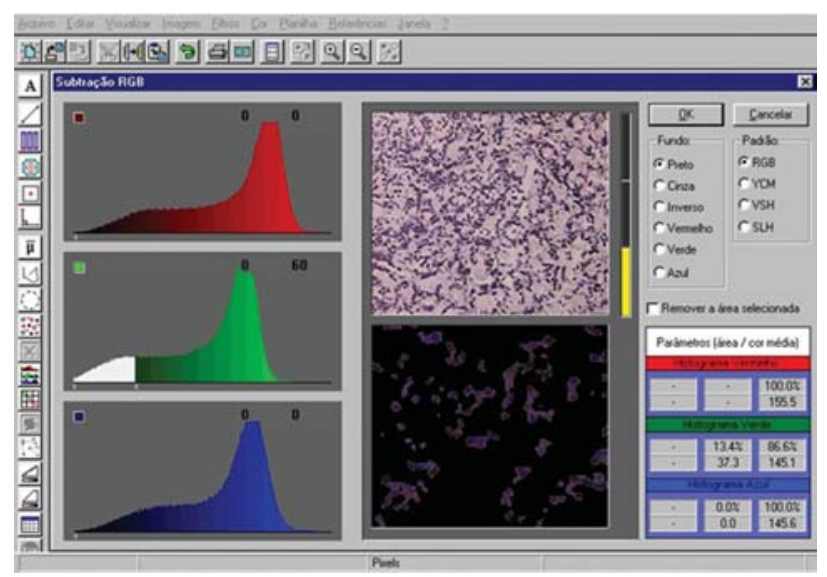

Figura 1. Imagem do software Imagelab 2000 informando a cor selecionada (quadrante central à esquerda), a imagem original (quadrante superior central), a área da imagem subtraída (quadrante inferior central) e a porcentagem das áreas removidas em relação à área da imagem original (quadrante inferior à direita).
Tabela 1. Média da porcentagem da área ocupada pela cor preta nas lâminas coradas pelo Verhoeff, nas camadas superficial, intermediária e profunda da prega vocal nos terços anterior, médio e posterior.

\begin{tabular}{lccc}
\hline & $\begin{array}{c}\text { Camada } \\
\text { Superficial }\end{array}$ & $\begin{array}{c}\text { Camada } \\
\text { Intermediária }\end{array}$ & $\begin{array}{c}\text { Camada } \\
\text { Profunda }\end{array}$ \\
\hline Anterior & 6,9 & 23,5 & 29,7 \\
Médio & 4,5 & 21,3 & 17,1 \\
Posterior & 10,4 & 23,3 & 25,0 \\
\hline
\end{tabular}

Tabela 2. Média da porcentagem da área ocupada pela cor preta nas lâminas coradas pela resorcin-fuchsin de Weighert nas camadas superficial, intermediária e profunda da prega vocal nos terços anterior, médio e posterior.

\begin{tabular}{lccc}
\hline & $\begin{array}{c}\text { Camada } \\
\text { Superficial }\end{array}$ & $\begin{array}{c}\text { Camada } \\
\text { Intermediária }\end{array}$ & $\begin{array}{c}\text { Camada } \\
\text { Profunda }\end{array}$ \\
\hline Anterior & 1,2 & 12,8 & 10,4 \\
Médio & 0,7 & 13,7 & 10,8 \\
Posterior & 0,5 & 7,8 & 5,5 \\
\hline
\end{tabular}

Tabela 3. Média da porcentagem da área ocupada pela cor marrom nas lâminas coradas pelo anticorpo policlonal contra tropoelastina humana, nas camadas superficial, intermediária e profunda da prega vocal nos terços anterior, médio e posterior.

\begin{tabular}{lccc}
\hline & $\begin{array}{c}\text { Camada } \\
\text { Superficial }\end{array}$ & $\begin{array}{c}\text { Camada } \\
\text { Intermediária }\end{array}$ & $\begin{array}{c}\text { Camada } \\
\text { Profunda }\end{array}$ \\
\hline Anterior & 8,8 & 12,2 & 10,1 \\
Médio & 7,3 & 12,0 & 12,3 \\
Posterior & 9,3 & 10,7 & 11,2 \\
\hline
\end{tabular}

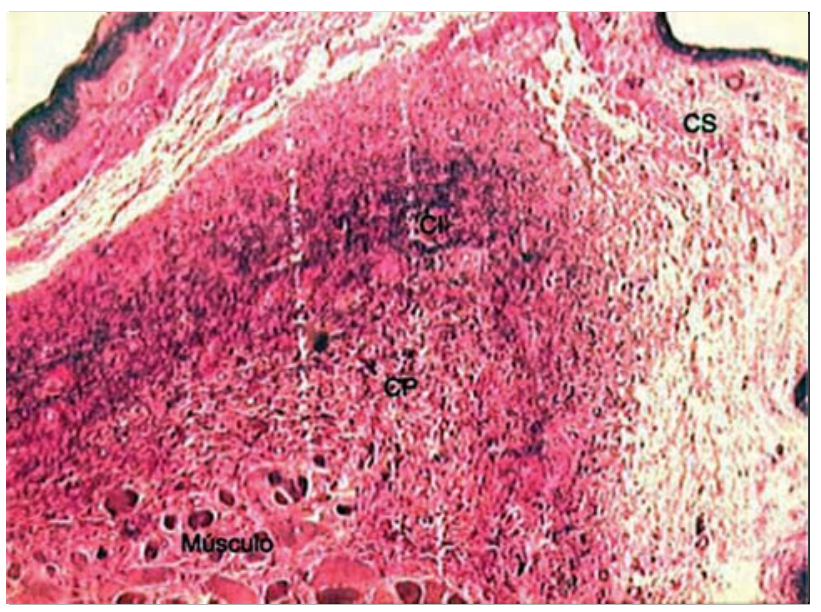

Figura 2. Distribuição das fibras elásticas nas camadas da lâmina própria coradas pelo Verhoeff. (Fragmento - 3, aumento $40 \mathrm{X}$ ). CS camada superficial, $\mathrm{Cl}$ - camada intermediária, $\mathrm{CP}$ - camada profunda. 
camadas intermediária e profunda da prega vocal apresentam valores muito superiores aos da camada superficial nas diferentes regiões da prega vocal. No entanto, podemos notar que a quantidade de tropoelastina identificada pelos anticorpos na camada superficial da LP encontra-se mais próxima aos valores das camadas intermediária e profunda.

A Figura 5 mostra, por meio da coloração resorcinfuchsin de Weighert, a presença de uma rede de fibras elásticas que corre logo abaixo da membrana basal. Interessante notarmos que entre esse plexo e a membrana basal do epitélio existe um espaço onde quase não há tecido elástico corado, só existindo alguns pequenos e raros pontos Corados de preto. Contudo, observando a Figura 6, notamos

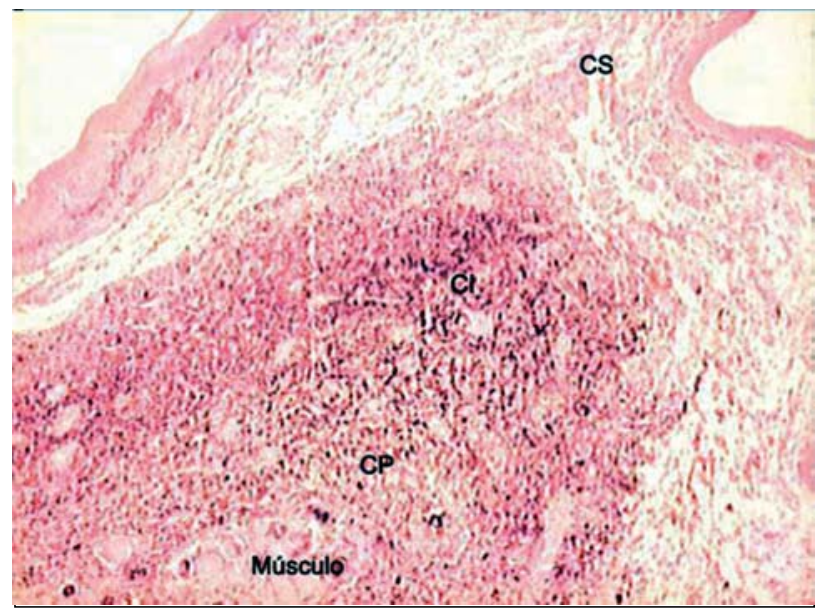

Figura 3. Distribuição das fibras elásticas nas camadas da lâmina própria coradas pela resorcin-fuchsin de Weighert. (Fragmento - 3, aumento $40 \mathrm{X}$ ). CS - camada superficial, $\mathrm{Cl}$ - camada intermediária, $\mathrm{CP}$ - camada profunda.

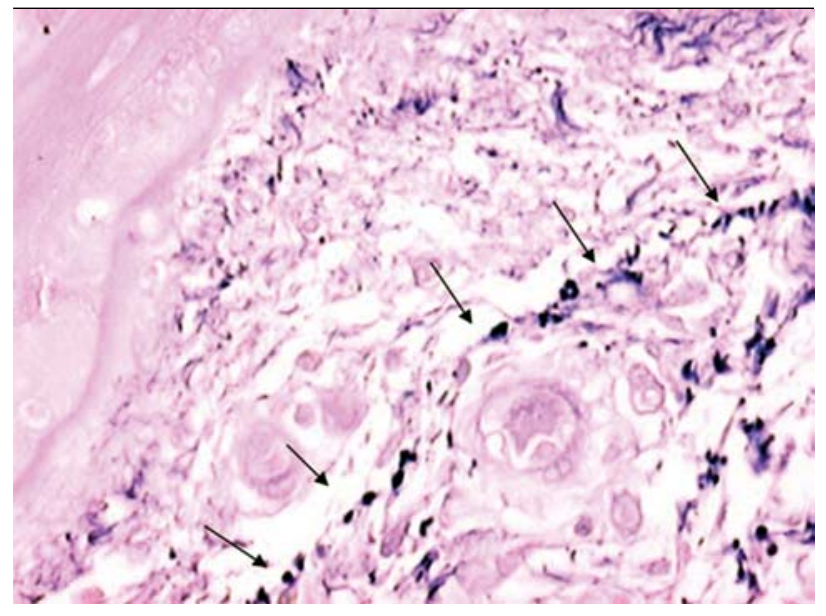

Figura 5. Plexo de fibras elásticas (setas) paralelo à membrana basal corado pela resorcin-fuchsin de Weighert. (Fragmento - 4, aumento $400 \mathrm{X})$. que o anticorpo pôde identificar tropoelastina nesta região situada adjacente à membrana basal.

\section{DISCUSSÃO}

Desde o trabalho pioneiro de $\mathrm{Hirano}^{1}$, a LP tem atraído a atenção dos laringologistas em todo o mundo. Ao propor a teoria do corpo e cobertura da fonação, Hirano lançou as bases sobre as quais toda a fisiologia da vibração da prega vocal tem se apoiado. Através de microscopia eletrônica, ele demonstrou que a camada média da LP é formada primariamente por fibras elásticas e que seu número diminui em direção à camada profunda.

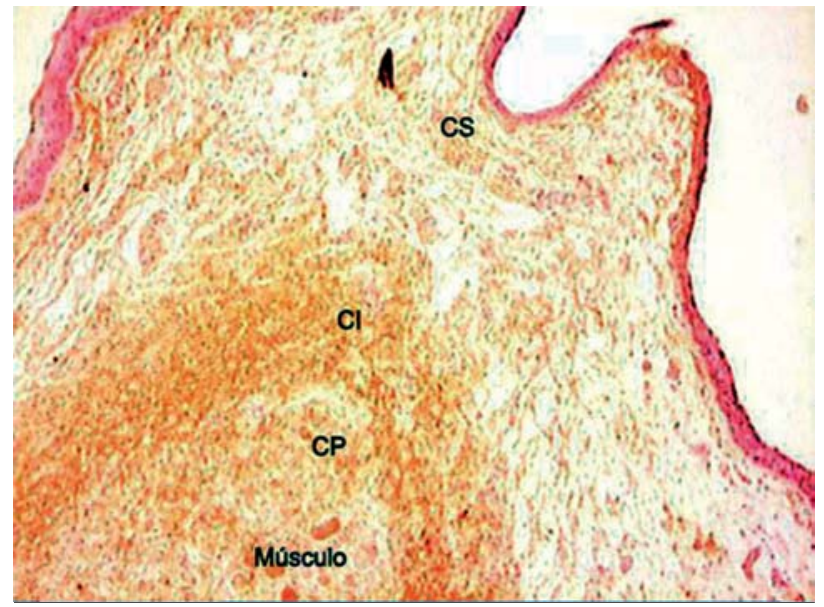

Figura 4. Distribuição da tropoelastina nas camadas da lâmina própria. (Fragmento - 4, aumento $40 \mathrm{X}$ ). CS - camada superficial, $\mathrm{Cl}$ camada intermediária, CP - camada profunda.

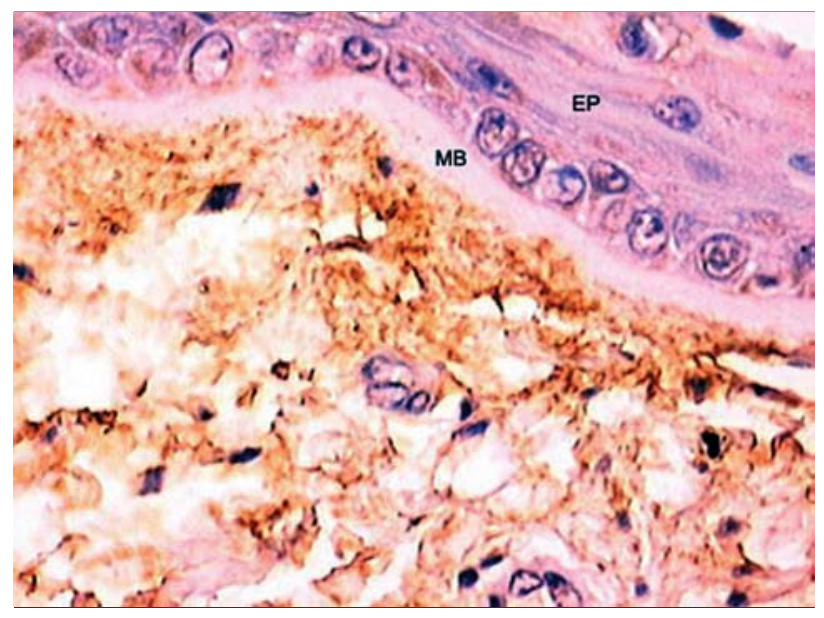

Figura 6 - Identificação da tropoelastina adjacente à membrana basal. (Fragmento - 4, aumento $400 \mathrm{X}$ ). EP - epitélio, MB - membrana basal. 
Procurando estudar o papel desempenhado pelas fibras elásticas na formação e propagação da onda mucosa da prega vocal, Hammond et al. ${ }^{2}$ utilizaram um sistema de análise de imagens para medir a quantidade de tecido elástico corado pelo Verhoeff em 40 laringes humanas e compararam os achados com estudo por microscopia eletrônica realizado em 6 laringes humanas. Confirmando os resultados de Hirano, os autores observaram que as fibras elásticas concentram-se principalmente na camada intermediária da prega vocal. Também descreveram que existem inúmeras pequenas fibras na camada superficial da LP, que, segundo os autores, corresponderiam às formas imaturas das fibras elásticas: elaunin e oxitalan. Acreditam que, por não se distenderem e por serem mais resistentes ao stress mecânico, as fibras oxitalânicas seriam mais abundantes na camada superficial.

Montes ${ }^{7}$, estudando as fibras elásticas em diferentes tecidos humanos, demonstra que o oxitalan localiza-se em áreas submetidas a stress mecânico: periodonto, junção dermo-epidérmica, endoneuro, corpo ciliar do olho etc. Na pele humana, as fibras oxitalânicas estão dispostas de forma perpendicular à junção dermo-epidérmica, juntas à membrana basal e conectadas a um plexo de fibras elaunínicas, que também encontram-se unidas a fibras elásticas maduras mais profundas. Os três tipos de fibras elásticas pertenceriam a um continuum em que o oxitalan, o elaunin e a fibra elástica madura conteriam coleções de microfibrilas com intensidades crescentes de substância amorfa. Embora esta seqüência corresponda às sucessivas fases da formação da fibra elástica, o autor acredita que a presença de fibras oxitalânicas e elaunínicas em tecidos que, mesmo plenamente maduros, não contêm fibras elásticas completamente formadas sugere que essas fibras tenham um papel estrutural específico.

Diferentemente dos autores acima, que se apoiaram na microscopia eletrônica para estudo morfológico das fibras elásticas da prega vocal, nosso estudo utilizou três tipos de colorações: o Verhoeff e a resorcina-fuchsina de Weighert, já utilizados anteriormente, e um terceiro tipo ainda não aplicado com esta finalidade, a imunohistoquímica.

Montes $^{7}$ descreve que as fibras elásticas imaturas são mais difíceis de serem coradas pelos métodos usuais e demonstra que o Verhoeff só é capaz de corar fibras que contêm substância amorfa e, por isso, consegue demonstrar apenas as fibras elásticas completas. O autor também mostra que o único método de coloração química que consegue identificar as fibras elaunínicas e as oxitalânicas é a resorcinfuchsin de Weighert, devendo as fibras oxitalânicas, no entanto, sofrer forte oxidação prévia.

Tradicionalmente, o oxitalan tem sido descrito como um feixe de microfibrilas de cerca de 10-12 nm de diâmetro que não contém substância amorfa. No entanto, Schwartz \& Fleischmajer ${ }^{8}$ demonstraram, por meio de imunofluorescência com anticorpos específicos para elastina e para microfibrilas, que o oxitalan está associado a pequenas quan- tidades de substância amorfa na pele humana.

A substância amorfa, chamada de proteína elastina, é formada por moléculas de tropoelastina que são secretadas pelas células para o espaço extracelular e se ligam covalentemente a outras subunidades. Nosso estudo demonstrou que o anticorpo foi capaz de identificar tropoelastina e, por conseguinte, substância amorfa em todas as camadas e ao longo de toda a lâmina própria da prega vocal humana. Até mesmo na região adjacente à membrana basal, onde se acredita estarem localizadas as fibras oxitalânicas, a imunohistoquímica mostrou a presença de tecido elástico (Figura 6). Ishii et al. ${ }^{3}$ já havia demonstrado, por meio de microscopia eletrônica, que o oxitalan localiza-se logo abaixo do epitélio escamoso da prega vocal humana, de forma semelhante ao que é encontrado na pele.

Diferentemente da ME, que identifica as estruturas por revelar a forma geométrica dos diversos componentes do tecido estudado, a imunohistoquímica o faz por meio da capacidade que o anticorpo tem de se ligar à estrutura para a qual foi formado. As estruturas que, por ventura, não tenham as mesmas características moleculares com as quais o anticorpo reage, não serão coradas e, por isso, não serão identificadas. Essa grande especificidade permite que o tecido estudado por meio da imunohistoquímica seja submetido a mensurações colorimétricas não realizáveis pela ME.

Também observamos, por meio da coloração resorcinfuchsin de Weighert, a presença de um plexo de fibras elásticas que corre paralelo e logo abaixo da membrana basal (Figura 5). Acreditamos que essa rede de fibras elásticas corresponda a fibras elaunínicas responsáveis pela conexão das fibras elásticas maduras profundas às fibras oxitalânicas subepidérmicas.

Sabemos que a liberdade de movimentos da cobertura da prega vocal está intimamente relacionada à quantidade de tecido vibrátil e à liberdade de movimentos em todas as direções por parte da LP e que a estrutura da matriz extracelular e a adequada distribuição das fibras elásticas podem ser decisivas nesse processo.

Até onde pudemos pesquisar, este é o único estudo que utiliza imunohistoquímica na identificação das fibras elásticas na prega vocal humana e nossos resultados nos mostram que esta técnica pode ser aplicada com este fim abrangendo todas as formas evolutivas das elásticas. Novos estudos com maior número de pregas vocais humanas devem ser realizados a fim de que tenhamos um profundo conhecimento sobre o papel desempenhado pelas fibras elásticas nos mecanismos biomecânicos envolvidos na produção da voz. Acreditamos que a mensuração das fibras elásticas por meio do anticorpo possa nos trazer estas informações.

\section{CONCLUSÃO}

Os resultados obtidos nos permitem concluir que a imunohistoquímica é uma técnica que identifica, em prega 
vocal humana, todas as formas de fibras elásticas e que também possibilita a realização de medidas objetivas.

\section{REFERÊNCIAS BIBLIOGRÁFICAS}

1. Hirano M. Phonosurgery: basic and clinical investigations. Otol Fukuoka 1975; 21: 239-45.

2. Hammond TH, Zhou R, Hammond EH, Pawlak A, Gray SD. The intermediate layer: a morphologic study of the elastin and hyaluronic acid constituents of normal human vocal folds. J Voice 1997; 11: 59-66.

3. Ishii K, Zhai WG, Akita M, Hirose H. Ultrastructure of the lamina propria of the human vocal fold. Acta Otolaryngol (Stockh) 1996; 116: $778-82$.
4. Sato K, Hirano M. Age-related changes of elastic fibers in the superficial layer of the lamina propria of vocal folds. Ann Otol Rhinol Laryngol 1997; 106: 44-8.

5. Midwood KS, Schwarzbauer JE. Elastic fibers: building bridges between cells and their matrix. Current Biology 2002; 12: R27981 .

6. Novelli MD, Barreto E, Matos D, Saad SS, Borra RC. Aplicação do processamento de imagens por computador na quantificação das variáveis histopatológicas da reparação tecidual de anastomoses colocólicas em cães. Rev Ass Med Brasil 1997; 43: 277-82.

7. Montes GS. Distribution of oxytalan, elaunin and elastic fibers in tissues. Ci Cult J Braz Ass Adv Sci 1992; 44: 224-33.

8. Schwartz E, Fleischmajer R. Association of elastin with oxytalan fibers of the dermis and with extracellular microfibrils of cultured skin fibroblasts. J Histochem Cytochem 1986; 34: 1063-8. 